\title{
INDICES OF OBESITY DERIVED FROM BODY WEIGHT AND HEIGHT
}

\author{
BY \\ T. KHOSLA AND C. R. LOWE \\ Department of Social and Occupational Medicine, Welsh National School of Medicine, Cardiff
}

The relation between body weight and mortality, particularly from cardiovascular disease and diabetes, is well established (Society of Actuaries, 1959; Preston and Clarke, 1966). A reliable, practicable, and generally acceptable index of obesity would therefore have important epidemiological, actuarial, and clinical applications; but many difficulties stand in the way of providing such an index.

Fat has a very different density from muscle and bone, so that one of the best indices is the specific gravity of the whole body, measured by water displacement. It is impracticable, however, to take the necessary measurements outside a specialized laboratory-total immersion would generally be regarded as too high a price to pay for a life policy -and even in the laboratory the measurements are not altogether reliable because of the varying volumes of gases in the air passages and the gastrointestinal tract. In busy clinical practice and in large-scale epidemiological surveys sophisticated methods of "somatotyping", whether based on photography (Sheldon, Stevens, and Tucker, 1940) or on anatomical measurements (Parnell, 1958), are also impracticable because of the time they take, apart altogether from questions of their reliability and interpretation. The measurement of skin-fold thickness has its uses but is subject to considerable site and observer variation and has the disadvantage that it demands what in epidemiological surveys may be an unacceptable amount of undressing (Edwards, Hammond, Healy, Tanner, and Whitehouse, 1955).

Because of these difficulties, weight in relation to height is commonly used as an index. Indices based on these two measurements have the unavoidable disadvantage that they take no account of muscularity or bone structure, but they have the great merit that the measurements themselves can be made easily, quickly, and with a fair degree of accuracy.

The three indices combining weight $(\mathrm{W})$ and height $(\mathrm{H})$ that have most often been used are:

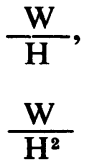

(sometimes called Quetelet's index),

$$
\text { and } \frac{\mathrm{H}}{\mathrm{W}^{\frac{1}{3}}}
$$

(often called the ponderal index).

Billewicz, Kemsley, and Thomson (1962) examined some of the properties of these indices. They found that all three appeared to correlate satisfactorily with relative adiposity, as estimated from body-density measurements. But when they were put to the test on weight, height, and age data for 6,000 primigravidae attending the Aberdeen Maternity Hospital, the simple ratio $\left(\frac{W}{H}\right)$ appeared to underestimate and the ponderal index $\left(\frac{\mathrm{H}}{\mathrm{W}^{\frac{1}{3}}}\right)$ to overestimate the amount of obesity among the short as compared with the tall women. Quetelet's index $\left(\frac{W}{\mathbf{H}^{2}}\right)$ showed very little bias in relation to height, but was considered unsatisfactory because it is tedious to calculate when large numbers of cases are involved and because its numerical value depends upon the units of measurement employed (e.g. inches and pounds, or centimetres and kilograms).

In this paper we re-examine the credentials of indices based upon weight and height, confirm that $\frac{W}{H^{2}}$ is much the best of them, suggest a method for calculating that index quickly without resort to an electronic computer, and illustrate its use in relation to original data on obesity and social class.

SOURCE OF DATA

The data used in the paper are derived from an epidemiological study of the distribution of arterial 
pressure in an industrial population (Lowe and McKeown, 1962; Lowe, 1964; Khosla and Lowe, 1965). They relate to more than 5,000 men employed by a large electrical engineering firm in Birmingham. The heights and weights of the men were measured and their blood pressures taken as they attended a mobile mass-radiography unit when it visited the firm in March, 1960. The men were asked to remove their coats, waistcoats, and shoes before they were measured. Their weights were taken on a large spring balance and recorded to the nearest pound; their heights were measured against a standard wall-scale and recorded to the half-inch below the observed point. All occupations from works manager to serviceman were included and the measurements can be accepted as reasonably representative of men employed in industry in the Midlands at that time.

\section{Theoretical Considerations}

We shall focus attention on three indices of obesity derived from weight and height:

$$
\begin{aligned}
& I_{1}=\frac{W}{H} \\
& I_{2}=\frac{W}{H^{2}} \times 100 \\
& I_{3}=\frac{W}{H^{3}} \times 10,000
\end{aligned}
$$

The index $\mathrm{I}_{3}$ is, of course, another way of expressing the ponderal index $\left(\frac{H}{W^{\frac{1}{3}}}\right)$. In its more usual form the ponderal index has the disadvantage that it is negatively correlated with weight and so decreases with increasing obesity. We shall use the form $\frac{W}{\mathrm{H}^{8}}$ to bring it into line with the other two indices, in which weight occurs in the numerator.

It seems clear that, in the general population, short persons are no more likely to be obese than tall ones (Billewicz and others, 1962). To be acceptable, therefore, any index of obesity derived from measurements of weight and height will need to satisfy the following two criteria:

(1) It must be highly correlated with weight;

(2) It must be independent of height (in the sense that for persons of standard weight at different heights the numerical value of the index should be the same).

Kemsley, Billewicz, and Thomson (1962) have shown that body weight and height are linearly related. The predicted standard weight $(\hat{W})$ for a given height $(H)$ can therefore be represented by the regression equation:

$$
\hat{\mathbf{W}}=\overline{\mathrm{W}}+b(\mathbf{H}-\overline{\mathbf{H}}) \ldots \ldots \ldots(\mathrm{A})
$$

where $\bar{W}$ is the mean weight, $\bar{H}$ the mean height, and $b$ the regression coefficient of weight on height.

To satisfy the criterion of independence of height, the obesity index will need to be invariant along the regression of standard weight on height. If we define the index as a function of weight and height of the general form $\mathrm{I}=\frac{\mathrm{W}}{\mathrm{H}^{n}}$, where $n$ is the power to which $\mathrm{H}$ must be raised to meet this criterion, it follows that:

$$
\mathbf{I}=\frac{\hat{\mathbf{W}}_{a}}{\mathbf{H}_{a}^{n}}=\frac{\hat{\mathrm{W}}_{b}}{\mathrm{H}_{b}^{n}} \ldots \ldots \ldots \ldots
$$

where $a$ and $b$ are any two points along the regression of standard weight on height. $\left(I_{1}, I_{2}\right.$, and $I_{3}$ are particular forms of the general index $\frac{W}{H^{n}}$ defined above.) From equation (B), taking log to the base 10, it follows that:

$$
n^{*}=\frac{\log \hat{\mathrm{W}}_{b}-\log \hat{\mathrm{W}}_{a}}{\log \mathrm{H}_{b}-\log \mathrm{H}_{a}} \ldots \ldots
$$

Let us apply these considerations to the 617 men aged 20-24 in the Birmingham sample. Their mean weight was 154.5 (s.d. $21 \cdot 6$ ) lb., their mean height was $68 \cdot 85$ (s.d. 2.62) in., and the regression coefficient of weight on height was $4 \cdot 30$. Substituting these values in equation $(A)$ we get:

$$
\hat{\mathrm{W}}=154 \cdot 5+4 \cdot 30(\mathrm{H}-68 \cdot 85)
$$

If we now take $61 \cdot 00$ and $76 \cdot 71$ in. $(H \pm 3$ s.d. $)$ as the extreme ends of the height distribution for this age group, we obtain from equation (A) predicted weights of 120.7 and $188.3 \mathrm{lb}$. for those extremes of height. Substituting these values in equation (C) we get:

$$
n=\frac{\log 188 \cdot 3-\log 120 \cdot 7}{\log 76 \cdot 71-\log 61 \cdot 00}=1.94
$$

This theoretical approach clearly favours the index $I_{2}\left(\frac{W}{H^{2}}\right)$, at least for the age group 20-24. We will now compare the performance of $I_{2}$ with that of $I_{1}$ and $I_{3}$ for other age groups in the Birmingham industrial population.

\footnotetext{
* In more general terms, the power " $n$ " is the regression coefficient of $\log W$ on $\log H$ (i.e. $\log W=\log I+n \log H)$.
} 
ZERO ORDER CORRELATION COEFFICIENTS BETWEEN STAN

\begin{tabular}{|c|c|c|c|c|c|c|c|c|c|c|c|c|c|c|c|c|c|c|c|}
\hline \multirow{3}{*}{$\begin{array}{l}\text { Age Group } \\
\text { Number } \\
\text { Indices }\end{array}$} & \multicolumn{4}{|c|}{ 15-19 } & \multicolumn{4}{|c|}{$20-24$} & \multicolumn{4}{|c|}{$25-29$} & \multicolumn{4}{|c|}{$30-34$} & \multicolumn{3}{|c|}{ 35-39은 } \\
\hline & \multicolumn{4}{|c|}{459} & \multicolumn{4}{|c|}{617} & \multicolumn{4}{|c|}{633} & \multicolumn{4}{|c|}{597} & \multicolumn{3}{|c|}{633 ज } \\
\hline & $\mathbf{H}$ & $\mathbf{W}$ & $\mathbf{I}_{1}$ & $\mathbf{I}_{2}$ & $\mathbf{H}$ & $\mathbf{W}$ & $\mathbf{I}_{1}$ & $\mathbf{I}_{2}$ & $\mathbf{H}$ & $\mathbf{W}$ & $\mathbf{I}_{1}$ & $\mathbf{I}_{2}$ & $\mathbf{H}$ & $\mathbf{W}$ & $\mathbf{I}_{1}$ & $I_{2}$ & $\mathbf{H}$ & $\mathbf{w}$ & 酌 \\
\hline $\mathbf{w}$ & $\cdot 59$ & & & & $\cdot 52$ & & & & .43 & & & & $\cdot 52$ & & & & $\cdot 53$ & & $\overline{\bar{\sigma}}$ \\
\hline $\mathbf{I}_{1}$ & $\cdot 37$ & .97 & & & $\cdot 28$ & .97 & & & $\cdot 19$ & .97 & & & $\cdot 30$ & .97 & & & $\cdot 30$ & .97 & $\frac{0}{9}$ \\
\hline $\mathbf{I}_{2}$ & $.075^{*}$ & $\cdot 85$ & .95 & & -.023 & $\cdot 84$ & .95 & & $-\cdot 100$ & $\cdot 85$ & .96 & & .017 & $\cdot 86$ & .96 & & .004 & .85 & 95 \\
\hline $\mathbf{I}_{\mathbf{3}}$ & $-\cdot 24$ & .63 & $\cdot 80$ & .95 & $-\cdot 32$ & $\cdot 63$ & $\cdot 81$ & .95 & $-\cdot 36$ & .68 & $\cdot 85$ & .96 & $-\cdot 27$ & $\cdot 67$ & $\cdot 83$ & .96 & $-\cdot 29$ & $\cdot 65$ & ${ }_{82}$ \\
\hline
\end{tabular}

Table I gives the zero order correlations between all possible pairs of the variables $\mathrm{H}, \mathrm{W}, \mathrm{I}_{1}, \mathrm{I}_{2}$, and $\mathrm{I}_{3}$ for each of the ten 5-yearly age groups from 15 to 65 years. The few correlation coefficients which are not significant at the 5 per cent. level are shown in italics. For each age group $I_{1}, I_{2}$, and $I_{3}$ satisfy the first criterion for an acceptable index of obesity-they are all highly correlated with weight. In this respect $I_{1}$ has the highest correlations $\left(r_{I_{1} w} \approx 0.97\right), \quad I_{2}$ comes next with correlations ranging from 0.83 to 0.86 , while $I_{3}$ has correlations that are consistently and appreciably lower than the other two (ranging from 0.60 to 0.68 ). However, $I_{2}$ alone satisfies the second criterion, that of being independent of height. For each age group $I_{1}$ is positively and $I_{3}$ negatively and quite highly correlated with height $(r \approx+0 \cdot 3$ and $-0 \cdot 3$ respectively). In comparison, the correlations between $I_{2}$ and height are all extremely low $(r \leqslant 0 \cdot 1)$ and except for one age-group are not significant. As would be expected, the three indices are themselves highly correlated with one another ( $r$ from 0.79 to 0.96 ).
Table II examines empirically the relative merits of the three indices in relation to standard weights $(\hat{W})$ at specified heights for the age group 20 to 24 years. The standard weights at the given heights are derived from equation (A). The values of the three indices have been calculated for standard weight at each of the seven specified heights. The figures in brackets express the value of the index at each of those heights as a percentage of the corresponding value at 63 in. For $I_{1}$ the percentage difference between the extreme heights is $17 \cdot 6$, for $I_{2}$ it is 0.9 , and for $I_{3}$ it is 16.9 . The Table 8 thus confirms that only $I_{2}$ is unbiased in relation to height; $I_{1}$ substantially overestimates obesity among taller persons and $I_{3}$ overestimates it among? shorter persons.

\section{Calculation of the Index $I_{2}$}

An index of obesity, however appropriate, will be of restricted use if a great deal of tedious arithmetic is involved in its calculation. The exact method of calculating the mean and standard deviation of $I_{2}$ for a large population is certainly tedious and costly.

TABLE II

STANDARD WEIGHTS AT SPECIFIED HEIGHTS Males aged 20-24

\begin{tabular}{|c|c|c|c|c|c|c|c|c|}
\hline Height (in.) & $63^{\prime \prime}$ & $65^{\prime \prime}$ & $67^{\prime \prime}$ & $69^{\prime \prime}$ & $71^{\prime \prime}$ & $73^{n}$ & $75^{\prime \prime}$ & Correlations \\
\hline Standard Weight $\hat{W}$ (lb.) & 129 & 138 & 147 & 155 & 164 & 172 & 181 & Index \\
\hline $\begin{array}{l}\hat{\mathbf{W}} \\
\hat{H}\end{array}=I_{1} \quad \ldots$ & $\begin{array}{l}2 \cdot 05 \\
(100)\end{array}$ & $\begin{array}{l}2 \cdot 12 \\
(103 \cdot 4)\end{array}$ & $\begin{array}{l}2 \cdot 19 \\
(106 \cdot 8)\end{array}$ & $\begin{array}{l}2 \cdot 25 \\
(109 \cdot 8)\end{array}$ & $\begin{array}{l}2 \cdot 31 \\
(112 \cdot 7)\end{array}$ & $\begin{array}{l}2 \cdot 36 \\
(115 \cdot 1)\end{array}$ & $\begin{array}{l}2 \cdot 41 \\
(117 \cdot 6)\end{array}$ & +0.28 \\
\hline $\begin{array}{l}\frac{\hat{W}}{H^{2}} 100=I_{2} \\
\text { (Per cent. of } 63^{\prime \prime} \text { value) } \ldots\end{array}$ & $\begin{array}{l}3 \cdot 25 \\
(100)\end{array}$ & $\begin{array}{l}3 \cdot 27 \\
(100 \cdot 6)\end{array}$ & $\begin{array}{l}3 \cdot 27 \\
(100 \cdot 6)\end{array}$ & $\begin{array}{l}3 \cdot 26 \\
(100 \cdot 3)\end{array}$ & $\begin{array}{l}3 \cdot 25 \\
(100)\end{array}$ & $\begin{array}{l}3 \cdot 23 \\
(99 \cdot 4)\end{array}$ & $\begin{array}{l}3 \cdot 22 \\
(99 \cdot 1)\end{array}$ & -0.02 \\
\hline $\begin{array}{l}\frac{W}{H^{3}} 10,000=I_{3} \\
\text { (Per cent. of } 63^{\prime \prime} \text { value) } \ldots\end{array}$ & $\begin{array}{l}5 \cdot 16 \\
(100)\end{array}$ & $\begin{array}{l}5 \cdot 02 \\
(97 \cdot 3)\end{array}$ & $\begin{array}{l}4 \cdot 89 \\
(94 \cdot 8)\end{array}$ & $\begin{array}{l}4 \cdot 72 \\
(91 \cdot 5)\end{array}$ & $\begin{array}{l}4 \cdot 58 \\
(88 \cdot 8)\end{array}$ & $\begin{array}{l}4 \cdot 42 \\
(85 \cdot 7)\end{array}$ & $\begin{array}{l}4 \cdot 29 \\
(83 \cdot 1)\end{array}$ & $-0 \cdot 32$ \\
\hline
\end{tabular}


GHT, BODY WEIGHT, AND THE INDICES $I_{1}, I_{2}, I_{3}$

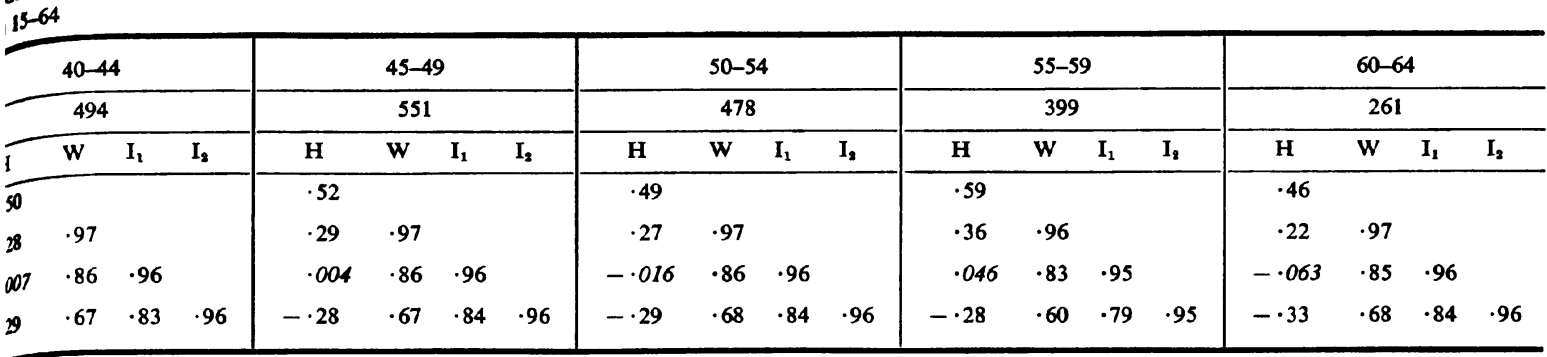

Mean weight $(\overline{\mathrm{W}})$ divided by mean height squared $(\overline{\mathbf{H}})^{2}$ will give an approximate value for the mean of the index $\left(\overline{\mathrm{I}}_{2}\right)$. This approximation was used by the American Army Authorities responsible for the statistical study of men enlisted for the first world war (quoted by Cathcart, Hughes, and Chalmers, 1935). For statistical purposes, however, the mean value of $I_{2}$ is of limited use unless the standard deviation of the index is also known. It can be shown (Cochran, 1953) that the standard deviation of a function of two variables of the form $\frac{\bar{W}}{\overline{\mathbf{H}}^{2}} \times$
100 ; is: s.d. $I_{2}=\frac{100}{\bar{H}^{3}} \sqrt{\bar{H}^{2} S_{W}^{2}+4 \bar{W}^{2} S_{H}^{2}-4 r_{W H} \bar{H} \bar{W} S_{W} S_{H}}$ where $r_{\mathrm{WH}}$ is the correlation coefficient of weight and height and $S_{W}$ and $S_{H}$ are the standard deviations of weight and height respectively.

In Table III we consider the "goodness" of the approximate methods of calculating $\overline{\mathrm{I}}_{2}\left(\frac{\overline{\mathrm{W}}}{\overline{\mathrm{H}}^{2}} \times 100\right)$ and of the standard deviation of $I_{2}$ by applying them to the Birmingham data. The results as calculated by exact and approximate methods are in excellent agreement.

The fact that the absolute value of the index $I_{2}$ depends upon the units of measurement employed (as, of course, must all indices based on height and weight) has been cited as a reason for not recommending its general use (Billewicz and others, 1962). This is not a serious objection. The index as calculated in pounds and inches is linearly related to the index as calculated in kilograms and centimetres by a factor of $14 \cdot 22$; so the one value may readily be converted to the other.

TABLE III

MEAN AND STANDARD DEVIATION OF BODY WEIGHT (bb.), STANDING HEIGHT (in.), AND OBESITY INDEX $I_{2}$ CALCULATED BY EXACT AND APPROXIMATE METHODS

\begin{tabular}{|c|c|c|c|c|c|c|c|c|c|c|c|}
\hline Age Group (yrs) & .. & $15-19$ & $20-24$ & $25-29$ & $30-34$ & $35-39$ & $40-44$ & $45-49$ & $50-54$ & $55-59$ & $60-64$ \\
\hline Number of Readings (N) & .. & 459 & 617 & 633 & 597 & 633 & 494 & 551 & 478 & 399 & 261 \\
\hline Mean Body Weight $(\bar{W})$ & . & $144 \cdot 6$ & $154 \cdot 5$ & $160 \cdot 2$ & $161 \cdot 4$ & $163 \cdot 2$ & $162 \cdot 5$ & $161 \cdot 2$ & $158 \cdot 3$ & $157 \cdot 2$ & $154 \cdot 4$ \\
\hline s.d. $\left(\mathbf{S}_{\mathbf{w}}\right)$ & . & $22 \cdot 29$ & $21 \cdot 64$ & $23 \cdot 16$ & $24 \cdot 32$ & $23 \cdot 41$ & $23 \cdot 82$ & $24 \cdot 89$ & $23 \cdot 91$ & $24 \cdot 84$ & $23 \cdot 18$ \\
\hline Mean Height* $(\overline{\mathbf{H}})$ & $\ldots$ & $68 \cdot 3$ & $68 \cdot 6$ & $68 \cdot 5$ & $68 \cdot 0$ & $67 \cdot 7$ & $67 \cdot 4$ & $67 \cdot 1$ & $66 \cdot 7$ & $66 \cdot 4$ & $65 \cdot 6$ \\
\hline s.d. $\left(\mathbf{S}_{\mathbf{H}}\right) \ldots$ & .. & $2 \cdot 86$ & $2 \cdot 62$ & $2 \cdot 59$ & $2 \cdot 60$ & $2 \cdot 59$ & $2 \cdot 57$ & $2 \cdot 64$ & $2 \cdot 62$ & $2 \cdot 92$ & $2 \cdot 58$ \\
\hline Correlation $\mathrm{W} \times \mathbf{H}\left(r_{\mathrm{WH}}\right)$ & $\cdots$ & $\cdot 59$ & .52 & .43 & .52 & .53 & .50 & .52 & .49 & .59 & .46 \\
\hline$I_{2}($ exact $)=\frac{\sum \frac{W}{H^{2}} \times 100}{N}$ & $\cdots$ & 3.09 & $3 \cdot 29$ & $3 \cdot 41$ & $3 \cdot 49$ & $3 \cdot 55$ & $3 \cdot 58$ & $3 \cdot 58$ & $3 \cdot 55$ & $3 \cdot 55$ & $3 \cdot 60$ \\
\hline $\begin{array}{llll}\text { s.d. } \mathbf{I}_{2} & \ldots & \ldots & \ldots \\
\end{array}$ & $\cdots$ & $\cdot 39$ & .39 & .45 & .45 & .43 & .45 & $\cdot 48$ & .47 & .45 & .48 \\
\hline $\begin{array}{llll}I_{2} \text { (approx.) } & =\frac{\overline{\mathrm{W}}}{\overline{\mathrm{H}}^{\mathrm{2}}} \times 100 \\
\text { s.d. } \mathrm{I}_{2} & \ldots & \ldots & \ldots\end{array}$ & $\begin{array}{l}\cdots \\
\cdots\end{array}$ & $\begin{array}{r}3 \cdot 10 \\
\cdot 39\end{array}$ & $\begin{array}{r}3 \cdot 28 \\
.39\end{array}$ & $\begin{array}{r}3 \cdot 41 \\
.45\end{array}$ & $\begin{array}{r}3 \cdot 49 \\
.45\end{array}$ & $\begin{array}{r}3 \cdot 56 \\
.43\end{array}$ & $\begin{array}{r}3 \cdot 58 \\
\cdot 45\end{array}$ & $\begin{array}{r}3 \cdot 58 \\
.47\end{array}$ & $\begin{array}{r}3 \cdot 56 \\
.47\end{array}$ & $\begin{array}{r}3 \cdot 57 \\
.45\end{array}$ & $\begin{array}{r}3 \cdot 59 \\
.48\end{array}$ \\
\hline
\end{tabular}

* Standing height was measured to $t^{\prime \prime}$ below; for comparison with other data 0.25 should therefore be added to the mean. The average effect on the index is to decrease $I_{2}$ by $0 \cdot 02$. No adjustment for centring has been made on this Table because the calculation by the exact method, which was carried out by computer, was based on observed readings. 
Application of $I_{2}$ to the Problem

of Obesity and Social Class

Despite an unparalleled improvement in the nutrition of the population of Britain since the beginning of the present century, there are still appreciable differences between the heights and weights of the different social classes, not only in childhood but also in adult life (Clements and Pickett, 1954; Tanner, 1962). In view of the wellknown relation between mortality from coronary disease and both obesity (Dawber, Kannel, Revotskie, Stokes, Kagan, and Gordon, 1959) and social class (Morris, Heady, Raffle, Roberts, and Parks, 1953), it would be of considerable interest to know whether or not the social classes differ also in respect of obesity. The paucity of evidence on this point is in part due to confusion about what constitutes a satisfactory index of obesity for epidemiological purposes.

In Table IV the men in the Birmingham survey have been grouped by age into monthly staff (salary paid in monthly instalments), weekly staff (salary paid in weekly instalments), and wageearners (men paid a weekly wage varying in relation to hours worked, overtime, piece work, etc.). These sub-divisions would be expected to correspond broadly with social class and general standard of living in the works population. The trend of weight with age is quadratic, at first increasing and then decreasing with increasing age (Fig. 1). The corresponding trend of height with age is linear, with a negative slope (Fig. 2, opposite). But the three subgroups differ strikingly in mean weight and height. At each age the monthly staff are from 5 to $9 \mathrm{lb}$. heavier than the wage-earners (Fig. 1). They are

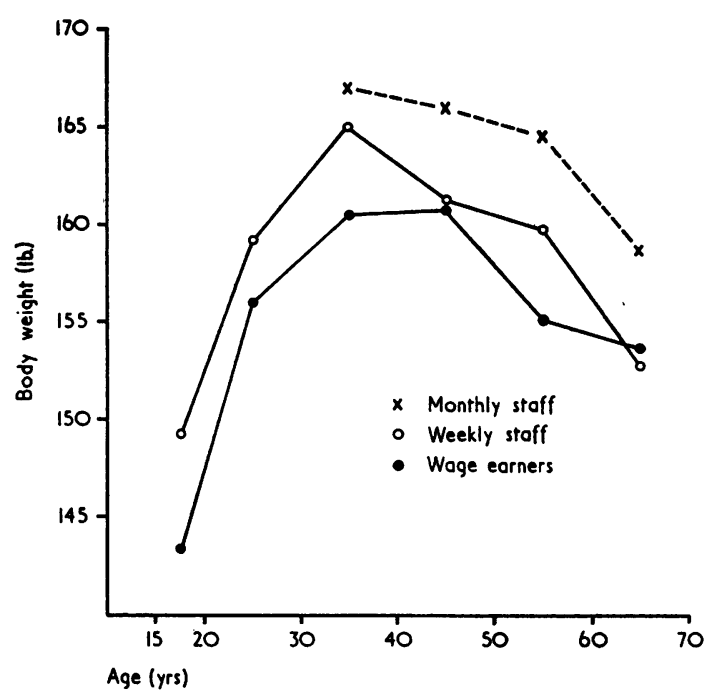

Fig. 1.-Body weight and works status.

also about 1.5 in. taller (Fig. 2). And for both measurements the weekly staff occupy an intermediate position. The great majority of the monthly paid staff and many of the weekly staff have sedentary occupations, whereas most of the wage earners are in jobs calling for moderate and if some cases for heavy physical effort. It is of some importance, therefore, to know whether the monthly and weekly staff are not only heavier and taller but are also more obese than the physically more active wage-earners. According to the index $I_{3}$, this is not so, in fact wage-earners appear to be

TABLE IV

MEAN WEIGHT, HEIGHT, INDEX $I_{2}$, AND WORKS STATUS Males aged 15-69

\begin{tabular}{|c|c|c|c|c|c|c|c|c|}
\hline & \multirow{2}{*}{ Measurement } & \multirow{2}{*}{ Works Status } & \multicolumn{6}{|c|}{ Age Group (yrs) } \\
\hline & & & $15-19$ & $20-29$ & $30-39$ & $40-49$ & $50-59$ & $60-69$ \\
\hline Fig. 1 & $\underset{(\mathrm{lb} .)}{\text { Mean Weight }(\overline{\mathrm{W}})}$ & $\begin{array}{l}\text { Monthly staff } \\
\text { Weekly staff } \\
\text { Wage earners }\end{array}$ & $\begin{array}{r}\overline{(0)} \\
149 \cdot 1 \\
(103) \\
143 \cdot 3 \\
(356)\end{array}$ & $\begin{array}{r}(20) \\
159 \cdot 1 \\
(566) \\
155 \cdot 8 \\
(664)\end{array}$ & $\begin{array}{c}167 \cdot 4 \\
(104) \\
165 \cdot 5 \\
(296) \\
160 \cdot 6 \\
(830)\end{array}$ & $\begin{array}{r}166 \cdot 3 \\
(117) \\
161 \cdot 5 \\
(260) \\
161 \cdot 2 \\
(668)\end{array}$ & $\begin{array}{r}164 \cdot 6 \\
(122) \\
159 \cdot 9 \\
(223) \\
155 \cdot 3 \\
(532)\end{array}$ & $\begin{array}{r}158 \cdot 9 \\
(41) \\
152 \cdot 8 \\
(85) \\
153 \cdot 2 \\
(204)\end{array}$ \\
\hline Fig. 2 & $\begin{array}{l}\text { Mean Height }(\overline{\mathbf{H}}) \\
\quad \text { (in.) }\end{array}$ & $\begin{array}{l}\text { Monthly staff } \\
\text { Weekly staff } \\
\text { Wage earners }\end{array}$ & $\begin{array}{r}- \\
69 \cdot 2 \\
68 \cdot 3\end{array}$ & $\begin{array}{r}- \\
69 \cdot 4 \\
68 \cdot 2\end{array}$ & $\begin{array}{l}69 \cdot 3 \\
68 \cdot 7 \\
67 \cdot 7\end{array}$ & $\begin{array}{l}68 \cdot 5 \\
67 \cdot 8 \\
67.2\end{array}$ & $\begin{array}{l}68 \cdot 2 \\
67 \cdot 2 \\
66 \cdot 4\end{array}$ & $\begin{array}{l}67 \cdot 1 \\
66 \cdot 1 \\
65 \cdot 3\end{array}$ \\
\hline Fig. 4 & $\begin{array}{c}\overline{\mathbf{I}}_{2}=\frac{\overline{\mathbf{W}}}{\overline{\mathbf{H}}^{\mathbf{2}}} \times 100 \\
\left.\text { (lb. per in. }{ }^{2}\right)\end{array}$ & $\begin{array}{l}\text { Monthly staff } \\
\text { Weekly staff } \\
\text { Wage earners }\end{array}$ & $\begin{array}{r}- \\
3 \cdot 11 \\
3 \cdot 07\end{array}$ & $\begin{array}{r}- \\
3 \cdot 30 \\
3 \cdot 35\end{array}$ & $\begin{array}{l}3 \cdot 49 \\
3 \cdot 51 \\
3 \cdot 50\end{array}$ & $\begin{array}{l}3 \cdot 54 \\
3 \cdot 52 \\
3 \cdot 57\end{array}$ & $\begin{array}{l}3 \cdot 53 \\
3 \cdot 54 \\
3 \cdot 53\end{array}$ & $\begin{array}{l}3 \cdot 53 \\
3 \cdot 50 \\
3 \cdot 60\end{array}$ \\
\hline
\end{tabular}




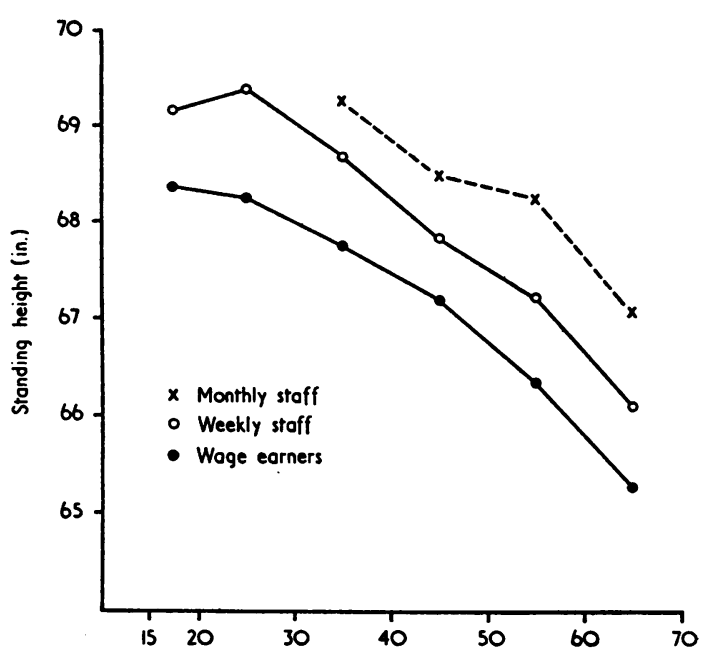

Age (yrs)

FIG. 2.-Standing height and works status.

substantially more "obese" than monthly staff (Fig. 3).

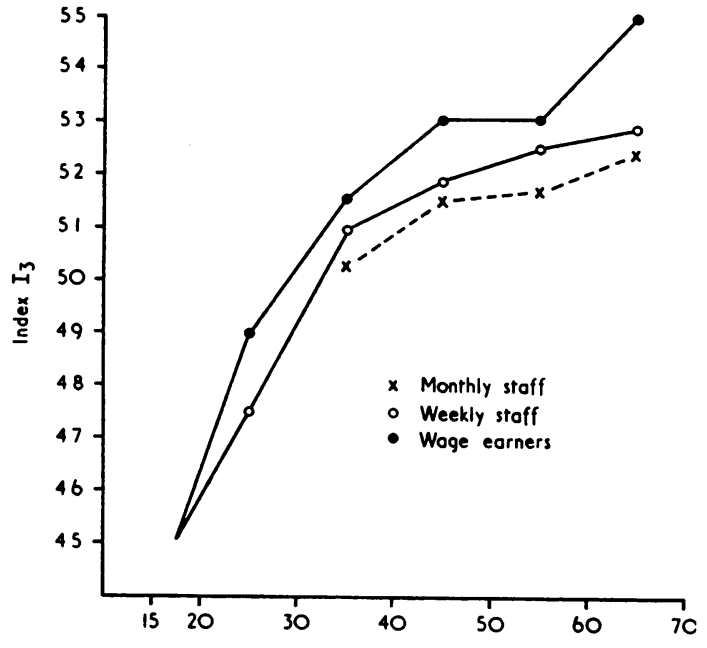

Age (yrs)

Fig. 3.-Index $I_{3}=\frac{W}{H^{3}} \times 10,000$ and works status.

The index $I_{2}$, on the other hand, suggests that the three groups are not differentiated in respect of obesity (Fig. 4). The two indices clearly give contradictory results.

An alternative method of comparing the trend of obesity in the three population sub-groups would be to adjust the mean body weights to a common height. The pooled, within-age, regression coefficient of weight on height for our data was

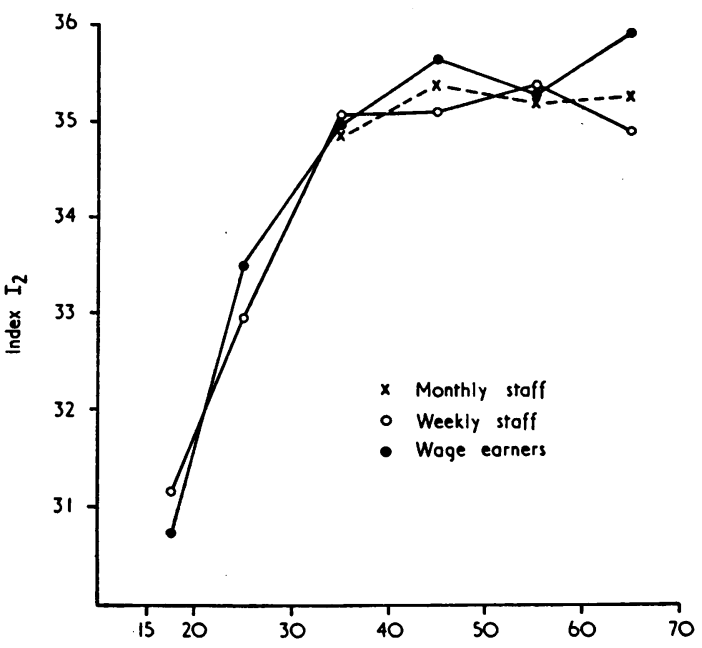

Age (yrs)

Fig. 4.-Index $I_{2}=\frac{W}{H^{2}} \times 10,000$ and works status.

$4.55 \mathrm{lb}$. per inch. For any sub-group, therefore, weight adjusted to a height of 68 in. would be calculated as follows:

Adjusted body weight $=\overline{\mathrm{W}}-4 \cdot 55(\mathrm{H}-68)$

We find that the trend displayed by this method (Fig. 5) agrees very closely with the trend as indicated by $I_{2}$ (Fig. 4), and it is reasonable to conclude that monthly and weekly staff are much heavier than the physically more active wage-earners, not because of their sedentary occupations but because of their greater height.

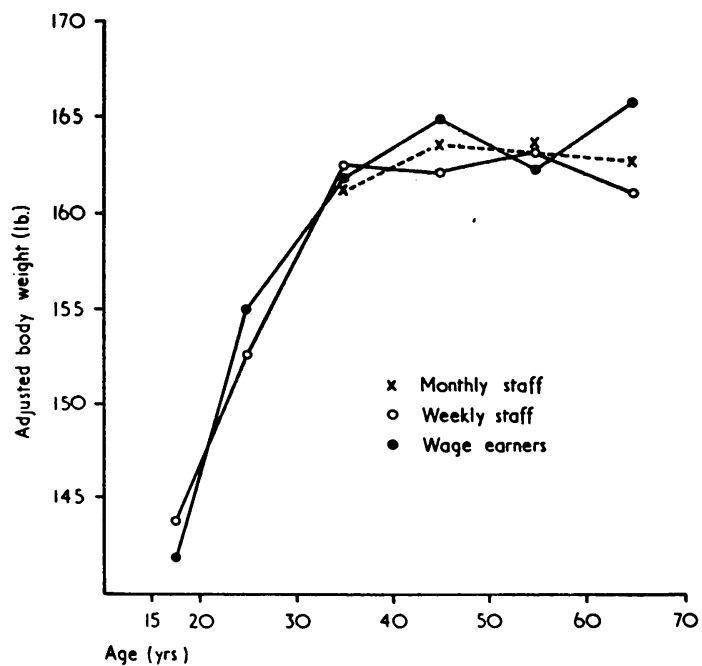

Fig. 5.-Adjusted body weights (at $68^{\prime \prime}$ height) and works status. 


\section{Discussion}

How obese a person is and how much he is overweight are not quite the same thing. Obesity implies an excessive amount of body fat, but a man may be overweight for his height because he is more muscular than average. Nevertheless, being obese and being overweight are closely related: if a man is obese he will almost certainly be overweight, and if he is much overweight he will certainly be obese. Because there is, as yet, no reliable method of measuring body fat which can be applied in the difficult circumstances of a large-scale epidemiological investigation, recourse must be had to indices of overweightness. A satisfactory index must, necessarily, be highly correlated with weight. We have shown that $I_{1}\left(\frac{W}{H}\right)$ is very highly correlated with weight $(r \approx 0.97)$. This index is unsatisfactory, however, because it is also positively correlated with height $(r \approx+0 \cdot 3)$, and there is good reason to believe that in the general population obesity is independant of height (Billewicz and others, 1962). The index $I_{3}\left(\frac{W}{H^{3}}\right)$ has the double disadvantage that it not only has a substantially lower correlation with weight $(r \approx 0.6)$ but also has a negative correlation with height $(r \approx-0 \cdot 3)$. The index $I_{2}\left(\frac{W}{H^{2}}\right)$ alone is both highly correlated with weight $(r \approx 0.85)$ and consistently independent of height. For this reason, and because it can be reliably estimated for grouped data from mean weight and mean height squared, we consider it to be the index of choice for epidemiological purposes.

It may be asked why the method of adjusting weight to a standard height is not preferable. The reason is that the procedure of adjusted body weight assumes that the regression lines of weight on height for the populations under comparison are parallel. If they are not, the difference between the adjusted weights will vary accordingly to the standard height chosen. And quite often they are not. For example, the regression coefficient of weight (lb.) on height (in.) for middle-aged men $(40-49)$ in the Birmingham industrial population in 1960 was 4.7 ; but for a sample of men of the same age, working in factories and mines in 1943, it was 3.8 (Kemsley, 1950). It would not be permissible, therefore, to compare the relative obesity of these two populations by the method of adjusted body weight. The index $I_{2}$, however, would be entirely appropriate.

The index $\frac{W}{\mathrm{H}^{2}} \times 100$, where $\mathrm{W}$ is the weight and $H$ the height of a person, is found to satisfy the following criteria necessary tor an epidemiological index of obesity:

(1) It is highly correlated with body weight $(r \approx 0.85)$.

(2) It is shown to be independent of height on the basis of both theoretical and empirical considerations.

(3) Its mean and standard deviation can readily be calculated by approximate methods which give results in excellent agreement with the much more laborious exact methods.

(4) It can readily be converted from pounds and inches to kilograms and centimetres.

The index is applied to measurement of height and weight in an industrial population in the Midlands. It is shown that although senior staff are much heavier, age for age, than wage-earners, they are not necessarily more obese, the greater part, perhaps all, of their excess weight being due to their greater height.

It is with pleasure that Prof. C. R. Lowe acknowledges his indebtedness to Prof. T. McKeown for advice and support when the data used in this paper were collected. The authors also wish to thank the Atlas Computer Unit at Harwell for their help and the Department of Physics, University College, Cardiff, for granting them access to their S.T.C. Zebra computer.

\section{REFERENCES}

Billewicz, W. Z., Kemsley, W. F. F., and Thomson, A. M. (1962). Brit. J. prev. soc. Med., 16, 183.

Cathcart, E. P., Hughes, D. E. R., and Chalmers, J. G. (1935). "The Physique of Man in Industry". M.R.C. industr. Hith Res. Bd, Report No. 71.

Clements, E. M. B., and Pickett, K. G. (1954). Brit. J. prev. soc. Med., 8, 99.

Cochran, W. G. (1953). "Sampling Techniques". Wiley, New York and London.

Dawber, T. R., Kannel, W. B., Revotskie, N., Stokes, J. Kagan, A., and Gordon, T. (1959). Amer. J. publ. Hlth, 49, 1349.

Edwards, D. A. W., Hammond, W. H., Healy, M. J. R., Tanner, J. M., and Whitehouse, R. H. (1955). Brit. J. Nutr., 9, 133.

Kemsley, W. F. F. (1950). Ann. Eugen., 15, 161.

, Billewicz, W. Z., and Thomson, A. M. (1962). Brit. J. prev. soc. Med., 16, 189.

Khosla, T., and Lowe, C. R. (1965). Ibid., 19, 159.

Lowe, C. R. (1964). Ibid., 18, 115.

and McKeown, T. (1962). Lancet, 1, 1086.

Morris, J. N., Heady, J. A., Raffle, P. A. B., Roberts, C. G., and Parks, J. W. (1953). Ibid., 2, 1053, 1111.

Parnell, R. W. (1958). "Behaviour and Physique". Arnold, London.

Preston, T. W., and Clarke, R. D. (1966). J. Inst. Actuaries, 92, 27.

Sheldon, W. H., Stevens, S. S., and Tucker, W. B. (1940). "The Varieties of Human Physique". Harper, New York.

Society of Actuaries (1959). "Build and Blood Pressure Study". Chicago.

Tanner, J. M. (1962). "Growth at Adolescence”, 2nd ed. Blackwell, Oxford. 